\title{
Discrete Dynamic Modeling Analysis of Engineering Management and Quality Optimization Innovation Mode Based on Big Data Intelligent Algorithm
}

\author{
Xiaowen Zhuang $(\mathbb{D}$ and Chuanbao Wu \\ Shandong University of Science and Technology, Qingdao 266590, Shandong, China \\ Correspondence should be addressed to Xiaowen Zhuang; xwzhuang@sdust.edu.cn
}

Received 9 November 2021; Accepted 9 December 2021; Published 28 January 2022

Academic Editor: Gengxin Sun

Copyright (C) 2022 Xiaowen Zhuang and Chuanbao Wu. This is an open access article distributed under the Creative Commons Attribution License, which permits unrestricted use, distribution, and reproduction in any medium, provided the original work is properly cited.

\begin{abstract}
With the advent of the big data era, information technology and intelligent algorithms are more and more widely used. In the engineering project management industry, big data technology and dynamic modeling have achieved good results. Enterprises attach great importance to the innovation of engineering project management. The establishment of engineering management and quality optimization innovation model can improve the management efficiency of engineering project process and enable enterprises to obtain great advantages in market competition. The use of big data technology can make project management and quality innovation more information-based and intelligent. Based on the above situation, this paper puts forward the research on discrete dynamic modeling of engineering management and optimization innovation mode based on big data intelligent algorithm. It mainly uses big data technology to collect and classify the obtained data information and uses discrete dynamic modeling technology to optimize the management system, focus on the management and innovation of green engineering, use big data dynamic modeling technology to build engineering management model, and improve the balance of project model through intelligent planning algorithm. The experimental results show that the big data intelligent algorithm combined with discrete dynamic modeling technology increases the applicability and feasibility of the system. The accurate data after big data analysis can be used for quality supervision and detection, which not only improves the project quality problems but also improves the management efficiency of the project.
\end{abstract}

\section{Introduction}

The management of engineering project is the summary of the establishment, implementation, and control of project plan. The current modern engineering project management process is relatively complex (Chen) [1]. Due to the change of dynamic engineering projects and the long management period, we need to improve it with the help of big data dynamic modeling. With the support of big data environment, we first need to understand the law of data change and carry out dynamic and intuitive regulation, to meet the diversified management needs of engineering project activities $(\mathrm{Xu})$ [2]. Therefore, in the era of big data, it is very important for the intelligent development and innovation of engineering project management. The basic big data technology can collect, process, and store most of the information generated in the project activities and finally realize the effective control of information and data. Taking building construction as an example, we use big data technology and intelligent algorithm to make the application data in the process of building use more accurate (Qin) [3]. It can greatly improve the management efficiency of construction projects and reduce the capital investment and labor cost in the process of project management. The establishment of a complete project system can make the management more effective, but in the current project management, most enterprises do not pay much attention to it. With the rapid development of information technology and big data technology, the design concept and construction mode of architectural engineering are 
transforming to the optimization mode (He) [4]. Although enterprises are keeping up with high and new technology, the development of engineering management is not perfect. The original management system can no longer meet the needs of modern engineering projects (Fan) [5]. In engineering management, how to realize green management and unified allocation of resources are also very important. At present, there are many stages and types of work in construction project management (Zhao) [6]. If we adopt a series of unified management models, it will bring negative effects. Therefore, in the diversified social development, we need to carry out innovative research on the project management model. In the construction process, the quality problem of the project is also the key content concerned by the enterprise managers. The quality of construction projects determines the speed of enterprise development. In the big data environment, we can use intelligent algorithms and discrete dynamic modeling technology to monitor and study project quality problems. In addition to using data mining and other technologies to obtain quality data, further preprocessing is needed. Then, the dynamic modeling model is used to establish the relevant detection mechanism (Zhou) [7].

In this paper, a project management and quality optimization model based on big data intelligent algorithm is proposed, and an innovative discrete dynamic modeling is carried out. The innovative arguments of this paper are as follows: (1) use data mining technology and big data analysis technology to integrate the data information generated in the process of project construction, and use the optimized path of intelligent algorithm for data preprocessing. (2) Precise control is achieved. Discrete dynamic modeling technology is used to solve the problem of dynamic data change. (3) The project management model built by BIM technology integrating big data discrete dynamic modeling improves the basic work efficiency. The accuracy of processing complex data is also significantly improved, which reduces the error rate caused by engineering construction dynamics.

This paper mainly includes three parts. The first part analyzes the background of engineering management and quality optimization mode under the big data environment and briefly describes the application status of big data technology and discrete dynamic modeling technology in various countries. The second part first analyzes the management requirements of engineering projects and establishes the relevant intelligent algorithm model to improve the system model from the aspects of system framework and functional modules. Then, the BIM green project management model is proposed to construct the management engineering structure of green cycle and control the project cost and project budget. Finally, the intelligent algorithm is used to analyze the engineering quality optimization mode and establish the discrete dynamic model. The third part is the result analysis of the research on green project management mode under big data intelligent algorithm, and the result analysis of the research on optimizing project quality based on dynamic modeling technology combined with intelligent algorithm.

\section{Related Work}

At present, the main factor affecting project management is that the management mode does not adapt to the development of the data age. The project management mode itself is a complex process. There are many management links for each project, and the types and working methods of engineering personnel are also different (Tian) [8]. This situation leads to the standardization of engineering management and the detection difficulty of quality management. The quality problems in engineering construction are also different from other production links, and the quality change is dynamic and unstable (Shang) [9]. There is a contradiction between instability and real time in general project quality. Therefore, the corresponding quality management and quality inspection must be improved in combination with the actual development status. Engineering management and quality optimization in the big data environment are still hidden. While completing the work, attention should be paid to the quality problems in the construction process, and most structures cannot directly see the advantages and disadvantages (Zhang Yitian et al.) [10]. Therefore, it is necessary to analyze and detect the concealment quality by means of discrete dynamic modeling technology or intelligent algorithm. This paper proposes big data intelligent algorithm and discrete dynamic modeling technology to solve the above problems.

At present, some European countries have made many achievements in developing big data technology. They use the scheduling function of the combination of intelligent algorithm and dynamic programming to study enterprise human resource management in the big data environment (Wang) [11]. This study constructs a discrete dynamic model based on big data to uniformly collect, regulate, and manage the dynamic changes of human resources. In the algorithm design, the scheduling function of intelligent algorithm is used as technical support. Compared with traditional algorithms, this research improves the work efficiency of human resource management system. It can effectively help enterprises improve the waste of manpower in management.

Big data technology and information technology have developed rapidly (Du) [12]. At present, information technology and education are the focus of all countries, so the development of digital education has been actively promoted. Education integrates a variety of modern intelligent technologies in the context of big data, improving learners' learning environment. In order to analyze scholars' learning motivation and emotional attitude, some education researchers use discrete dynamic modeling technology to obtain quantitative learning data. The obtained data are analyzed and extracted to realize the dynamic model construction of learners' personalized learning (Xu) [13].

Modern technology has been able to apply big data dynamic modeling technology to data storage (Dai Dan et al.) [14]. The optimized database function and system structure are widely used in finance, digital, telecommunications, and other industries. This model mainly uses the understanding of user needs and user data information as the data source of analysis and supports the functions of 
location query and automatic division. This storage method greatly improves the efficiency of system management.

China's big data technology is also developing rapidly, and dynamic modeling is widely used in various fields (Yin et al.) [15]. In geological research, 3D dynamic modeling combines the organic system of big data to improve the efficiency and quality of geological model. Researchers have proposed a three-dimensional dynamic model based on geological data to deal with the problems of data collection, data analysis, data storage, and so on. Based on the development status of big data intelligent algorithm and discrete dynamic modeling technology in various countries, this technology is also used in engineering project management and quality inspection.

\section{Methodology}

3.1. Research on Dynamic Modeling of Green Project Management Mode Based on Big Data Intelligent Algorithm. By analyzing the future development trend of the engineering industry, it can be seen that intelligence is one of the main development directions of the construction industry. Managers should be good at adopting more intelligent management means, that is, big data cluster intelligent technology to manage engineering projects. With the support of big data cluster intelligent technology, managers can realize the digital management of construction projects across time and space and can carry out integrated management from planning and design, construction to operation. In the future intelligent engineering, the site can be regarded as an integrated assembly site connected by multiple supply chains and a variety of manufacturing industry combinations. Therefore, in the construction project management, managers need to achieve the collaborative management of all links. In site management activities, there are many modern technologies that can be applied, including large-scale data acquisition and analysis technology, red technology, and image recognition technology represented by UAV, so as to obtain construction site data at a higher frequency, highlight benefits, and improve quality.

As the concept of green engineering building has attracted more and more attention, this paper also constructs the corresponding green engineering management model in the research. Firstly, combined with the information data of data mining, the data processed by BIM of building model is added to the storage database for green engineering management and optimization. The specific factors affecting green project management are analyzed, and the data is processed by means of big data analysis and dynamic modeling. In order to realize green project management and BIM information control analysis, the corresponding management database is established first. The big data information is preprocessed and added to the project management task table. Combined with intelligent algorithm rules, green engineering information is fused. Finally, the green project management scheme is constructed according to the results of information fusion. The specific process is shown in Figure 1.
It can be seen from Figure 1 that, after establishing the task list, information fusion needs to be carried out in combination with the actual situation of the project. The final project management scheme is not only applicable, but also real-time and dynamic. Through the green management and scientific management of project construction, the structural model is realized, cost regulation and mechanism improvement are carried out, the project budget and cost budget are integrated, and the analysis rules related to project management are established. Finally, the control function in green engineering project management is obtained as follows:

$$
\text { st }=\sum_{j=1}^{m}(U, A, R)+\operatorname{RL}(M, N, Y) .
$$

Here, $(U, A, R)$ represents the unsalable data of project cost management, and $(M, N, Y)$ represents the constraint function after rule association analysis. The distribution structure of green management control sources is carried out through the project control function. Finally, the engineering management interpretation variables and the control function analysis model are obtained. The specific formula is as follows:

$$
\max Z=s t+\sqrt{\frac{x_{i j}+c_{i j}}{2}}
$$

where $x_{i j}$ in the formula represents the explanatory variable data of green project management. Through the above formula analysis, the control data results of green project management can be obtained. A certain threshold is designed to control the distribution structure of data sources, and the final management optimization function of the model is realized. In order to improve the accuracy of the analysis model in the big data environment, we need to mark the data with feature vectors combined with discrete dynamic modeling technology. Firstly, the equilibrium of the model is optimized by distributed allocation, and the obtained correlation value of engineering project management is expressed by variable function. The eigenvector of green engineering management is described as

$$
x=\mathrm{SCM}_{h \min }+\Psi \sqrt{\frac{\left(\Psi_{i}+\alpha\right)^{2}}{2}},
$$

where the variable represents the initial probability of green building project management data allocation. Assuming that the BIM information dimension of the whole model is fixed, the calculated edge distribution function expression is

$$
M^{\mathrm{B}}=\sum_{x e M} f(x)+\beta|x+1|^{2} .
$$

The reliability of the data set is detected to obtain the reliable data set. Obtain BIM information attribute distribution formula through data preprocessing and tag analysis:

$$
P \subseteq S+M^{\mathrm{B}}[\alpha \beta] .
$$




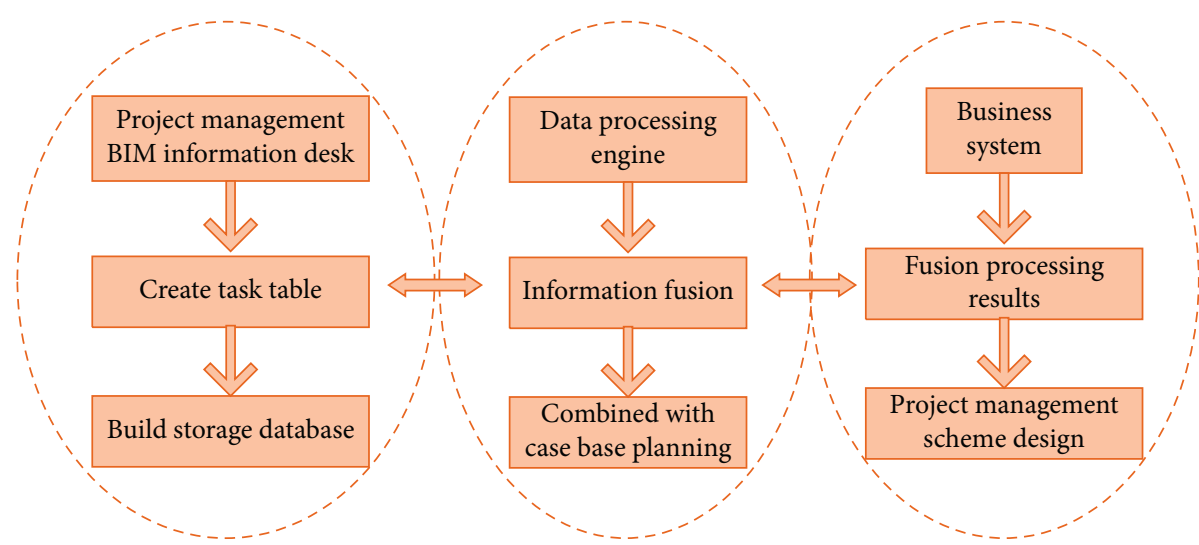

FIgURE 1: Green project management flowchart.

Combined with the dynamic spatial reorganization method, the intelligent algorithm equation of BIM data for green engineering management is obtained:

$$
w_{k}=x_{k}-\int_{2}^{k} f\left(x_{k-1}\right)-h\left(x_{k}\right) \mathrm{d} x .
$$

Here, the variable $f\left(x_{k-1}\right)$ represents the attribute set of data samples, and $h\left(x_{k}\right)$ represents the fusion of statistical parameters. The dynamic multiattribute decision-making method can be combined with the BIM information model to build the management structure, and the expression is

$$
\operatorname{ind}(P)=w^{2}+\sum_{\forall a \in p} M^{\beta}+x_{2} .
$$

Combined with the above formula analysis, the relevant information of green project management after discrete dynamic modeling can be obtained, so as to optimize the traditional project management model. We build the system model in the big data environment through BIM information access and resource reorganization and define the BIM information regression expression as

$$
M=\frac{\sqrt{\left(M^{\beta}-x\right)^{2}+\left(M^{\beta}+x\right)^{2}}}{\operatorname{ind}(P)} .
$$

The characteristic spectrum of management data obtained under different construction conditions and project management environment under dynamic change process is calculated by formula. According to the density distribution and difference of green project management data, the change data and range are calculated. The derivative of discrete dynamic eigenvector is calculated, and the results of project management are intelligently analyzed according to the set evaluation system. We compare the advantages and disadvantages of traditional project management system and green project management system, as shown in Figure 2.

As can be seen from Figure 2, the data feedback efficiency of the green project management system has increased significantly. This result proves that big data intelligent algorithm and discrete dynamic modeling optimization management system can improve the efficiency of system operation. It greatly saves labor cost and time cost.

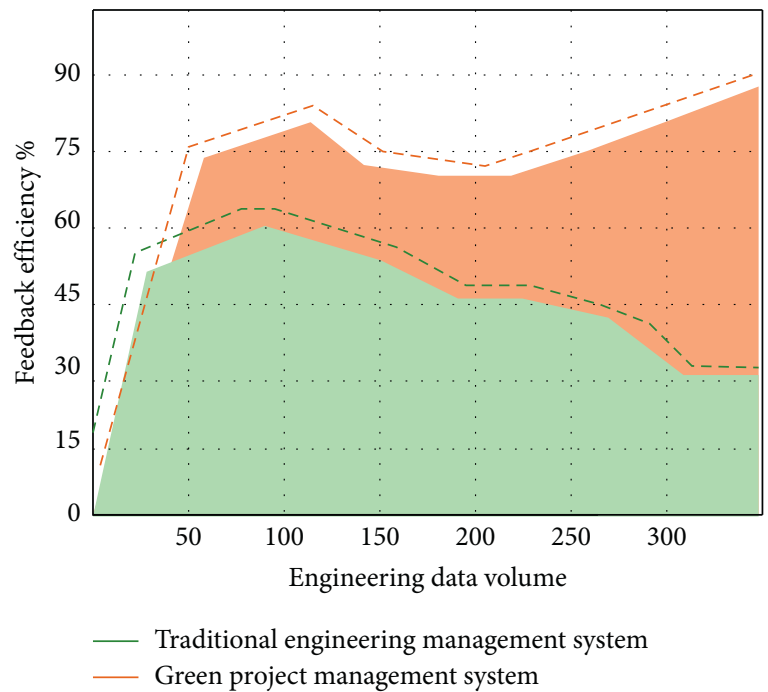

FIgURE 2: Advantages and disadvantages of the traditional engineering management system and green engineering management system.

\subsection{Research on Discrete Dynamic Modeling of Engineering} Quality Optimization Innovation Mode Based on Big Data Intelligent Algorithm. To establish the project management mode under the big data environment, it is necessary to analyze the requirements of system functions. The project management system mainly uses information technology and big data technology and takes the data trace of the project construction process as the data source of management, including project quality and safety management, construction scheme design management, and equipment resource management. In the traditional project management, enterprises often ignore the dynamic and real-time nature of project management and project quality problems. The pursuit of duration and cost brings risks and hazards to the quality of the project. With the state's increasingly strict supervision on the dynamic nature of enterprise project management, enterprises begin to pay attention to the efficiency and quality of management. Therefore, we establish a discrete dynamic system for green project management mode based on big data intelligent algorithm. The main influencing factors of project management are shown in Figure 3. 


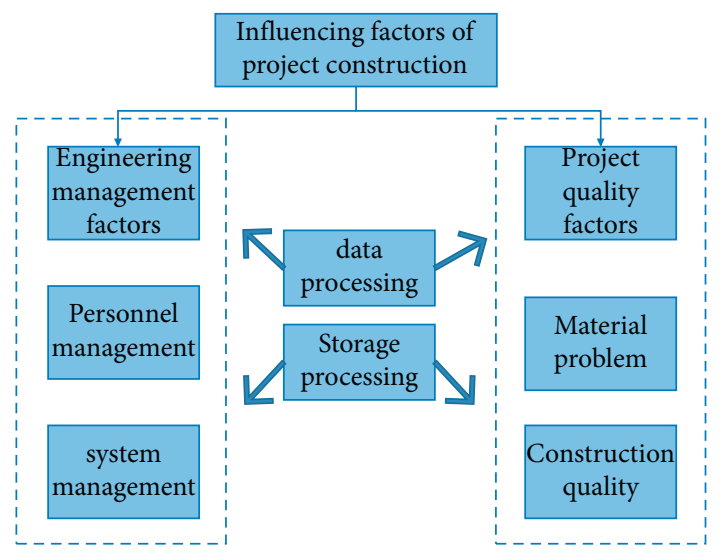

FigURE 3: Main influencing factors of project management.

It can be seen from Figure 3 that the establishment and development of engineering project are a complex structure and process, including many links and contents. The regulation of construction quality and management can directly affect the development of engineering projects. Among them, we first analyze the human factors. The main core of management is personnel. The problems in operation are mainly the basic quality and ability of staff. Managers should focus on the professional ability and comprehensive quality of engineering personnel and establish the corresponding internal audit model, adjust and control personnel's posts through scores and evaluation, and ensure that project management personnel can establish high-quality project implementation plan. Finally, in the actual project, the quality of materials also directly affects the project quality. When purchasing materials, quality inspection and cost control are required. According to the specifications of the project, find materials with high cost performance as the main body. In the process of material preservation, it is also necessary to record the quality, quantity, model, etc. of each material. Strict requirements on the storage environment ensure the safety of qualified quality. Therefore, facing the data problem in complex environment, we use discrete dynamic modeling to optimize the engineering quality problem. First, in order to dynamically model requirements, we first assume that the engineering project is ongoing. The construction process of each project must comply with the corresponding sequence, and construction beyond the level is not allowed. The construction time of the project is also limited and cannot be less than the shortest time. According to the assumptions, we get the following calculation formula and define the objective function as

$$
(x, \delta)=\max _{(h, n)}\left[E_{h i}+\delta_{h i}-x_{h i}\right] .
$$

Then, the overall time of the project is

$$
T(x, \delta)=\max _{(h, n)}\left[E_{h n}+\delta_{h n}-x_{h n}\right] .
$$

The actual cost controlled according to the project time is

$$
C(x, \delta)=C_{i j}^{c}+\left(\frac{C_{i j}^{N}-C_{i j}^{C}}{\delta_{i j}-t_{i j}}\right) \times\left(\delta_{i j}-X_{i j}-t_{i j}^{C}\right) .
$$

The total cost control calculated for the project is

$$
C(x, \delta)=\sum_{(i j) \in A} C_{i j}^{c}+\left(\frac{C_{i j}^{N}-C_{i j}^{C}}{\delta_{i j}-t_{i j}}\right) \times\left(\delta_{i j}-X_{i j}-t_{i j}^{C}\right) .
$$

During project construction, the actual quality of each project is expressed as

$$
Q(x, \delta)=Q_{i j}^{c}+\left(\frac{Q_{i j}^{N}-C_{i j}^{C}}{\delta_{i j}-t_{i j}}\right) \times\left(\delta_{i j}-X_{i j}-t_{i j}^{C}\right) .
$$

The total project quality obtained by data weighting processing by discrete modeling system is

$$
Q(x, \delta)=\sum_{(i j) \in A} w_{i j}\left(Q_{i j}^{c}+\left(\frac{Q_{i j}^{N}-C_{i j}^{C}}{\delta_{i j}-t_{i j}}\right) \times\left(\delta_{i j}-X_{i j}-t_{i j}^{C}\right)\right) .
$$

When calculating the actual situation of project quality, we also need to consider the limitation of rush time. The specific influencing factors take the materials used in the actual construction as the analysis data.

In engineering construction, coal is often used as the material. Traditional processing masters control the proportion of coal use according to various indicators of coal and experience. The quality of coal shall be allocated according to linear calculation. Then, the specific value of coal quality index is predicted by unified linear regression, and the use demand of engineering construction is met by adjusting the proportion of coal materials. However, the simple linear regression calculation method cannot accurately judge the impact of coal use on project quality. In particular, coal materials containing metals are easy to be affected by thermal indexes. Therefore, this paper uses discrete dynamic modeling technology to study the influence of coal allocation index on engineering quality. Firstly, the corresponding ratio prediction model is established. The model error is reduced to less than $5 \%$, and the data results and practical experience are used for macrocontrol. We take the matching samples as the objective function to build a dynamic optimization model. Firstly, the quantity range of single coal is determined, and the formula of cost function is shown as follows:

$$
\min f(x)=\sum_{j=1}^{n} C_{j} x_{j}
$$

For each proportioning range, there is a specific limit value to control the quality change. In order to get the optimal result of engineering quality, we also need to use intelligent algorithm for optimization. Based on the dynamic changes of big data, the intelligent algorithm can establish a random search model to eliminate interference data. In order to ensure that the project quality optimization model can play a relative role, we also need to integrate the quality control and project management system in combination with the actual development of project construction. Big data technology and scientific algorithms are used as data support and theoretical support. The efficiency of project 
management is strengthened and a good foundation is laid for construction quality. In addition, it is also necessary to establish a quality monitoring system corresponding to multiple links such as manpower, materials, and equipment, select a reasonable inspection mechanism, and establish incentive rules, to improve the enthusiasm and efficiency of staff.

\section{Result Analysis and Discussion}

4.1. Analysis of Research Results of Dynamic Modeling of Green Project Management Mode Based on Big Data Intelligent Algorithm. With the wide application of big data model, we have explored various ways of project management. Most of the management modes optimize project management according to modern technology. BIM, big data technology, and virtual reality technology are used to regulate and monitor the project site. Using data mining and big data analysis to obtain management data makes the analysis data more accurate and effective, which makes us able to provide applicable guidance for the site of plant management. In the process of project management, managers also need to pay attention to data analysis and obtain and collect on-site data information of the project and do a good job in the unified processing and storage of data to achieve the purpose of intelligent overall management. Due to the complexity of engineering data in big data environment, it has real-time and dynamic characteristics. Therefore, the data form is prone to structural changes. We also use discrete dynamic modeling technology to study the diversity of data. Firstly, complex and duplicate information data are deleted to purify the availability of data content. Finally, the characteristic variables are classified and marked uniformly. The management model processed in this way can greatly improve its work efficiency. In green project management, this paper uses a construction unit project as data support. In green project management, this paper uses BIM information fusion as the last step of data processing. The traditional management mode is compared with the optimized project management model, as shown in Figure 4.

It can be seen from Figure 4 that, with the increase of engineering data information, the efficiency of information processing of the optimized green engineering project management system has been significantly improved. Compared with engineering management, the error coefficient is also small. In green project management and information optimal scheduling allocation, the constrained characteristic statistics not only help the system reduce the error coefficient but also improve the operation feedback efficiency. Through the joint implementation of cost control and quality inspection, the information allocation and integration management in green engineering are integrated, which improves the stability of the management system. Therefore, the traditional project management mode is no longer suitable for construction projects in the big data environment. The green management system optimized by big data technology needs to be used as the equipment support for the construction of engineering projects.

4.2. Analysis of Research Results of Discrete Dynamic Modeling of Engineering Quality Optimization Innovation Mode Based on Big Data Intelligent Algorithm. At present, most engineering enterprises pay less attention to construction quality and control. In the project quality management and optimization, a wide range of contents and links is involved. In order to ensure the quality and cost control of the construction process, we need professional managers and quality inspectors. In the actual quality optimization, we often pay attention to the supervision effect and ignore the coverage of project quality. The above situation is very unfavorable to the development of enterprises. Therefore, we need to regulate and optimize the project quality from many aspects.

Taking the coal ratio of engineering materials as an example, this paper uses the coal quality data of an engineering project in 2020 as the calculation data of the estimation model. Firstly, the influence of coal proportioning quality on the total quality of the project is predicted, and the dynamic data modeling of the project quality optimization model is carried out. In the discrete dynamic model, after a variety of detection and application of system functions, we develop the quality problem of engineering materials, which greatly affects the optimization of engineering quality. Then, we conduct discrete data analysis on the project quality and actual input cost, and the specific results are shown in Figure 5 .

It can be seen from Figure 5 that the prediction model of discrete dynamic modeling can explain the causes of influencing factors of project quality. With the decline of coal quality, the overall construction quality of the project has also decreased significantly. For projects with high actual cost, the number of engineering quality problems is less. If the actual construction cost is limited under a certain coefficient, the number of engineering quality problems will increase. Therefore, we need to optimize the project quality model. In the optimization model, the prediction accuracy of discrete dynamic modeling system is high, which has some advantages over traditional modeling technology. Be able to make timely adjustments according to the dynamic changes of data.

In this paper, data mining technology and big data analysis technology are used to integrate the data information generated in the process of project construction, and the optimized path of intelligent algorithm is used for data preprocessing. Precise control is realized. Therefore, discrete dynamic modeling technology is used to solve the problem of dynamic data change. BIM technology integrates the project management model established by big data discrete dynamic modeling, which improves the basic work efficiency. The accuracy of processing complex data has also been significantly improved, so as to reduce the error rate caused by engineering construction dynamics. 

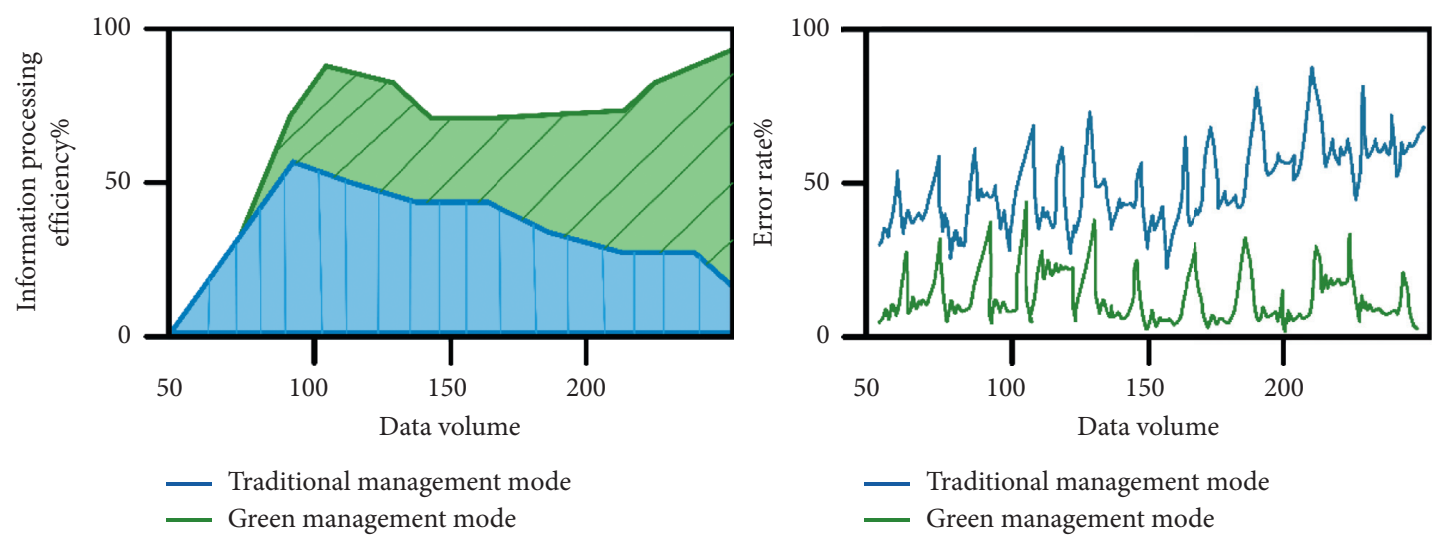

FIgURE 4: Performance comparison between the traditional management mode and optimized project management model.

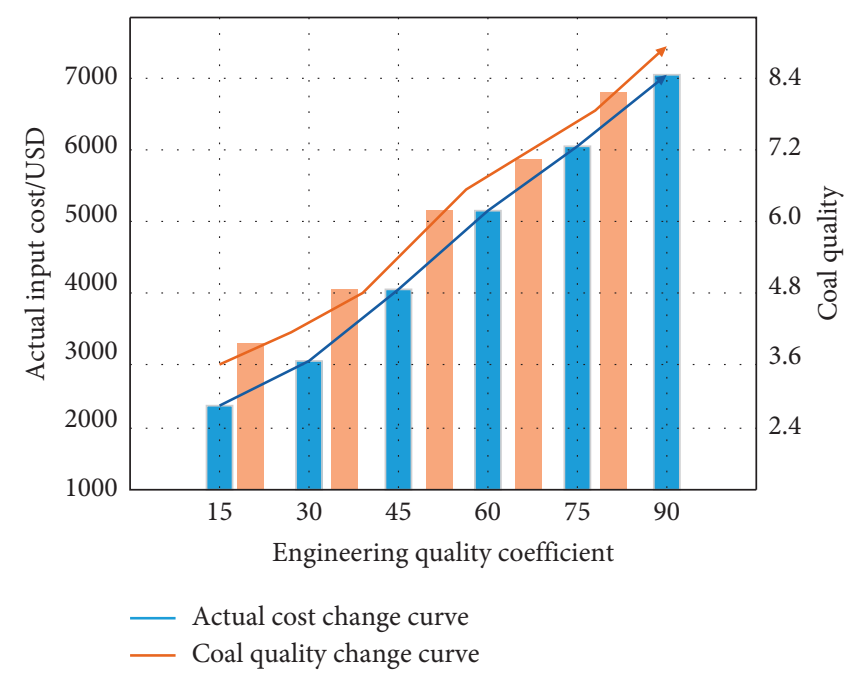

FIGURE 5: Analysis chart of project quality and actual input cost.

\section{Conclusion}

At present, with the continuous improvement of national engineering construction quality management requirements, the traditional engineering management and quality monitoring are not suitable for the current development status. More and more enterprises begin to seek more advanced engineering project construction management methods. The problems in engineering construction also increase. Material quality, management mechanism, and internal audit are the main factors affecting project development and enterprise development. Facing this situation, this paper proposes a project management and quality optimization model based on big data intelligent algorithm and carries out innovative discrete dynamic modeling at the same time. Firstly, data mining technology and big data analysis technology are used to integrate the data information generated during project construction, and the optimized path of intelligent algorithm is used for data preprocessing. In view of the complexity of engineering structure caused by too much information in big data environment, discrete dynamic modeling technology is used to solve the problem of dynamic data change. Finally, the BIM technology is integrated into the project management model, the intelligent algorithm is used to balance the project time and cost, and the corresponding dynamic model is established. In the research of engineering quality problems, this paper applies discrete modeling technology to engineering construction quality evaluation. The corresponding prediction model is established to analyze the impact of material quality and personnel professionalism on the total quality of the project. The experimental results show that the engineering management model constructed by BIM technology integrating big data discrete dynamic modeling improves the basic work efficiency. The accuracy of processing complex data is also significantly increased, which reduces the error rate caused by the dynamics of engineering construction. In project quality monitoring, discrete dynamic model can accurately predict the changes of factors affecting project quality problems, which is convenient for project managers to make corresponding countermeasures. However, the design results adopted in this paper lack professional managers and quality inspectors in the quality and cost control of the construction process. Therefore, the content of this paper needs to be improved in practical application. This will be gradually improved in future research. 


\section{Data Availability}

The data used to support the findings of this study are available from the corresponding author upon request.

\section{Conflicts of Interest}

The authors declare that they have no conflicts of interest.

\section{Acknowledgments}

This work was supported by Shandong University of Science and Technology.

\section{References}

[1] H. Jin, Y. Fu, and G. Yang, "An intelligent scheduling algorithm for resource management of cloud platform," Multimedia Tools and Applications, vol. 79, no. 7, pp. 5335-5353, 2020.

[2] J. Xu, "Research on intelligent analysis and processing technology of financial big data based on clustering algorithm," Electronic Design Engineering, vol. 29, no. 15, pp. 102-105, 2021.

[3] Z. Cao, L. Zhou, B. Hu, and C. Lin, "An adaptive scheduling algorithm for dynamic jobs for dealing with the flexible job shop scheduling problem," Business \& Information Systems Engineering, vol. 61, no. 3, pp. 299-309, 2019.

[4] R. Foresti, S. Rossi, M. Magnani, C. Guarino Lo Bianco, and N. Delmonte, "Smart society and artificial intelligence: big data scheduling and the global standard method applied to smart maintenance," Engineering, vol. 6, no. 7, pp. 835-846, 2020.

[5] B. W. Bequette, "110th anniversary: commentary: the smart human in smart manufacturing," Industrial \& Engineering Chemistry Research, vol. 58, no. 42, pp. 19317-19321, 2019.

[6] K. Mahroof, "A human-centric perspective exploring the readiness towards smart warehousing: the case of a large retail distribution warehouse," International Journal of Information Management, vol. 45, pp. 176-190, 2019.

[7] G. Zhang, P. Brown, and G. Li, "Research on personal intelligent scheduling algorithms in cloud computing based on BP neural network," Journal of Intelligent \& Fuzzy Systems, vol. 37, no. 3, pp. 3545-3554, 2019.

[8] L. Yang, G. Jiang, and X. Chen, "Design of integrated steel production scheduling knowledge network system," Cluster Computing, vol. 22, no. 4, pp. 10197-10206, 2019.

[9] D. A. Rossit, F. Tohmé, and M. Frutos, "A data-driven scheduling approach to smart manufacturing," Journal of Industrial Information Integration, vol. 15, pp. 69-79, 2019.

[10] Y. Zhang, X. Liu, and B. Li, "Study on Optimization of quality supervision mode of building materials in Shenzhen," Project Quality, vol. 39, no. S1, pp. 1-4, 2021, + 12.

[11] A. Bousdekis, K. Lepenioti, D. Apostolou, and G. Mentzas, “A review of data-driven decision-making methods for industry 4.0 maintenance applications," Electronics, vol. 10, no. 7, p. 828, 2021.

[12] F. Longo, L. Nicoletti, and A. Padovano, "Ubiquitous knowledge empowers the smart factory: the impacts of a service-oriented digital twin on enterprises' performance," Annual Reviews in Control, vol. 47, pp. 221-236, 2019.

[13] M. Parente, G. Figueira, P. Amorim, and A. Marques, "Production scheduling in the context of industry 4.0: review and trends," International Journal of Production Research, vol. 58, no. 17, pp. 5401-5431, 2020.

[14] D. Dai, Z. Cai, and B. Zhang, "Discrete dynamic system modeling and elastic control of knowledge workers in hightech enterprises," Journal of China University of Metrology, vol. 32, no. 1, pp. 109-117, 2021.

[15] C. Yin, L. Gao, and X. Li, "Modeling and analysis of production logistics network in discrete manufacturing workshop based on complex network theory," Computer Integrated Manufacturing System, vol. 26, no. 8, pp. 2157-2169, 2020. 